\title{
Probiotics-Derived Peptides and Their Immunomodulatory Molecules Can Play a Preventive Role Against Viral Diseases Including COVID-19
}

\author{
Sounik Manna ${ }^{1} \cdot$ Trinath Chowdhury $^{2} \cdot$ Ranadhir Chakraborty $^{3} \cdot$ Santi M. Mandal $^{2}$ (D) \\ Accepted: 1 November 2020 / Published online: 23 November 2020 \\ (C) Springer Science+Business Media, LLC, part of Springer Nature 2020
}

\begin{abstract}
As of recent, the pandemic episode of COVID-19, a severe acute respiratory syndrome brought about by a novel coronavirus (SARS-CoV-2) expanding the pace of mortality, has affected the disease rate profoundly. Invulnerability is the fundamental choice to prevent the ruining event of COVID-19, as the drugs and antibodies are in the phase of preliminary clinical trials. Within this brief period, a few strains of SARS-CoV-2 have been recognized by the vaccine manufacturers, which could be an incorrect guess about the strain that will end up spreading. Since the circulating SARS-CoV-2 strains continue to mutate, immunizations, if at all works, might be for a restricted time. We have not put sufficient time in research to understand the immune responses that correlate with protection as this could help refine vaccines. Here, we have summed up the adequacy of the immunomodulatory component of probiotics for the prevention against viral infections. Furthermore, an in silico data have been provided in support of the "probiotics-derived lipopeptides" role in inactivating spike (S) glycoprotein of SARS-CoV-2 and its host receptor molecule, ACE2. Among well characterized lipopeptides derived from different probiotic strains, subtilisin (Bacillus amyloliquefaciens), curvacin A (Lactobacillus curvatus), sakacin P (Lactobacillus sakei), lactococcin Gb (Lactococcus lactis) was utilized in this study to demonstrate a higher binding proclivity to S-protein of SARS-CoV-2 and human ACE2. The outcome revealed noteworthy capabilities of the lipopeptides, due to their amphiphilic nature, to bind spike protein and receptor molecule, which may act to competitively inhibit the mandatory interaction of SARS-CoV-2 with the host epithelial cell expressing ACE2 for its entry into the cell for reproduction. In the current situation, probiotic treatment alongside chemotherapy may assist in bringing about substantial improvement of the health of COVID-19 patients. At the same time, probiotics may aid towards building up the immune defenses in people to evade COVID-19.
\end{abstract}

Keywords Probiotics $\cdot$ Immunomodulatory $\cdot$ Peptides $\cdot$ SARS-CoV-2 $\cdot$ COVID-19

\section{Introduction}

More than 200 viruses in the environment are known to infect humans, and their number is increasing sharply in recent past [1]. The diseases caused by Zika [2], Ebola [3], respiratory syncytial virus (RSV) [4], severe acute respiratory syndrome virus (SARS) [5], and as of the latest episode of severe acute

Sounik Manna and Trinath Chowdhury contributed equally to this work.

Santi M. Mandal

mandalsm@gmail.com

1 Department of Microbiology, Midnapore College (Autonomous), Paschim Medinipur, India

2 Central Research Facility, Indian Institute of Technology Kharagpur, Kharagpur 721302, India

3 Department of Biotechnology, North Bengal University, Darjeeling, India respiratory syndrome coronavirus-2 (SARS-CoV-2) [6] are really existential threats to human beings. Researchers, worldwide, involved in the innovating drugs are in a process of developing vaccine or therapeutics. The genomes of SARS$\mathrm{CoV}-2$ are generated at a rate similar to changes in virus transmission.

In everyday life, challenges come all the more forcefully where just invulnerability has been the most ideal alternative to battle against SARS-CoV-2. The host is prepared to battle with various methods of immune defense against viral pathogens to eliminate them from the infecting organs and system. The immune response to a viral infection is primarily brought about by the lymphocytes. However, the quantity of lymphocytes that can perceive and respond against any individual sort of virus is at first exceptionally little. This is especially valid for a novel virus, for example, SARS-CoV-2, which individuals have never experienced. Hence, as to create a compelling immune response, the modest number of lymphocytes that can 

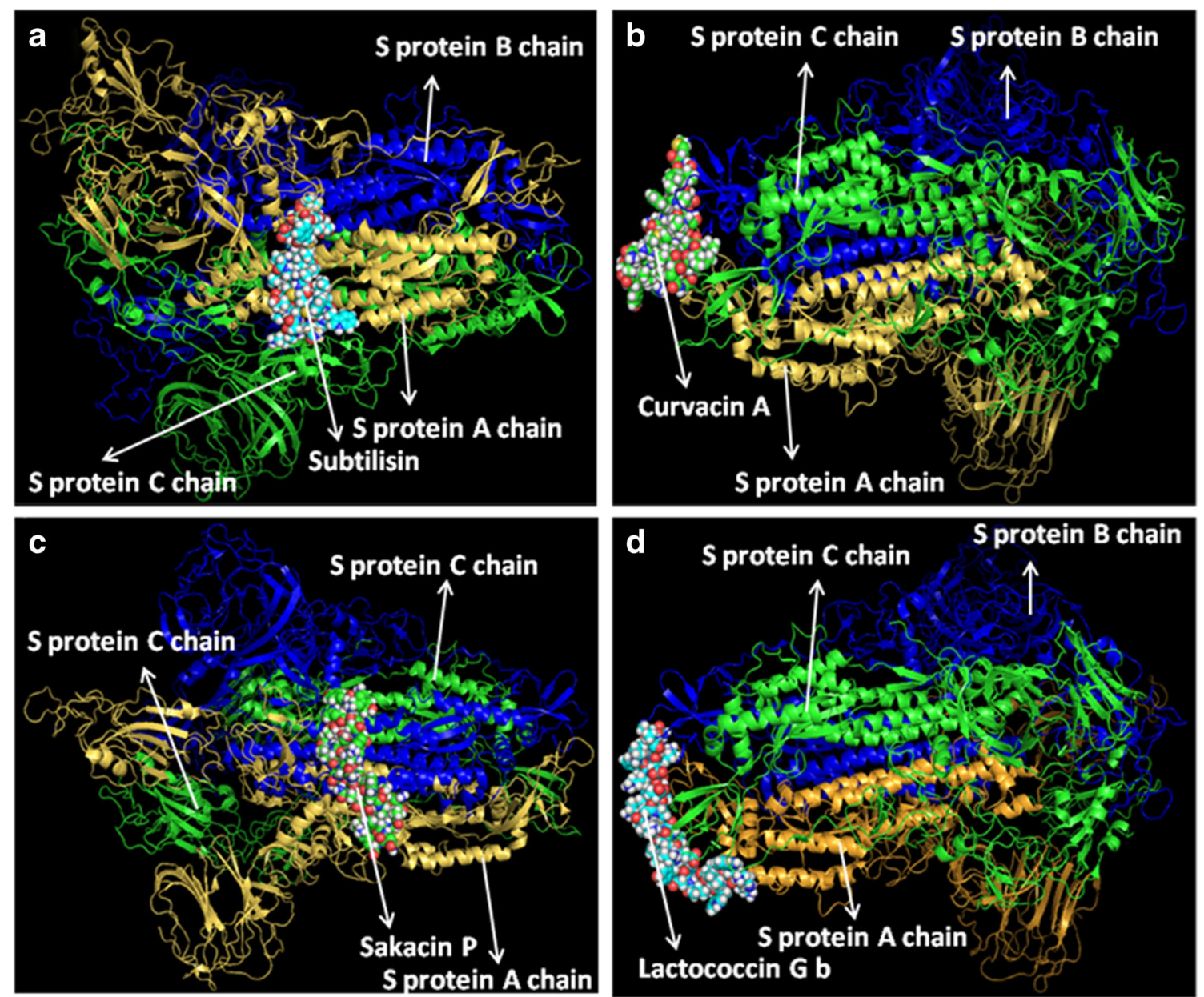

Fig. 1 Molecular docking analysis of the binding interactions for predicted lipopeptides and S-protein complex. Visualized images are representing the complexes of subtilisin and S-protein (a), curvacin and S-protein (b), sakacin P and S-protein (c), and lactococcin GB and S-protein (d)

perceive a virus must turn out to be increasingly bountiful. Even though lymphocytes multiply rapidly, it despite everything takes a few days before there are adequate cells accessible to avenge against the contagion. During this period, the virus may likewise be spreading quickly, so there is a race between the virus and the immune system that may decide the ultimate result, in terms of recovery.

The host has a number of immune defense functions that can eradicate viruses and/or viral disease. A variety of specific and nonspecific mechanisms contribute towards immunity to viral infection. Virus's interaction with the host cells and its mechanism to transmit dictates the process of activation of different immune functions and the duration and extent of the immune response of the host. During the acute phase of virus infections, nonspecific responses via inhibition, natural killer cell activity, and interferon restrict virus multiplication. Shortly after, specific immune responses (humoral and cellmediated) take over the task to get rid of virus at the end of the acute phase and then to sustain specific resistance to reinfection [7]. Yet, a good number of patients develop serious viral disease-associated symptoms because of the varying nature of immunity, caused by complex heritable traits and environmental factors, that influence person to person differently.

Therefore, in the battle against the onslaught of COVID19 , the only strategy remained at our disposal is to develop immunity against viral infection. Extensive researches, with the objective to boost immune function, have revealed probiotic as one of the most important therapeutic amendments to activate the required immunity in human beings. Probiotic microorganisms contribute significantly towards enhancing nutrient absorption through the digestive system, synthesis of vitamins, and means to protect against pathogens with the aid of bacterial secondary metabolites. Several effective probiotics were found to enhance the immunomodulatory effect through the modulation of the mucosal immune system towards long-lasting health $[3,4]$. Again, probiotic administration is a low-cost, safe, and noninvasive approach to nullify the adverse properties of antibiotic misuse on the microbiota [8].The probiotics are well typified by the Lactobacillus spp. that are able to induce different physiological and immunological processes against different viral infections [9]. It was documented that the action of natural killer $\mathrm{T}$ cells was up- 
Fig. 2 In silico analysis of the binding interactions between RBD of SARS-CoV-2 and lipopeptides. The images are representing the complex of RBD with subtilisin (a), sakacin $\mathrm{P}$ (b), curvacin A (c), lactococcin $\mathrm{Gb}(\mathbf{d})$
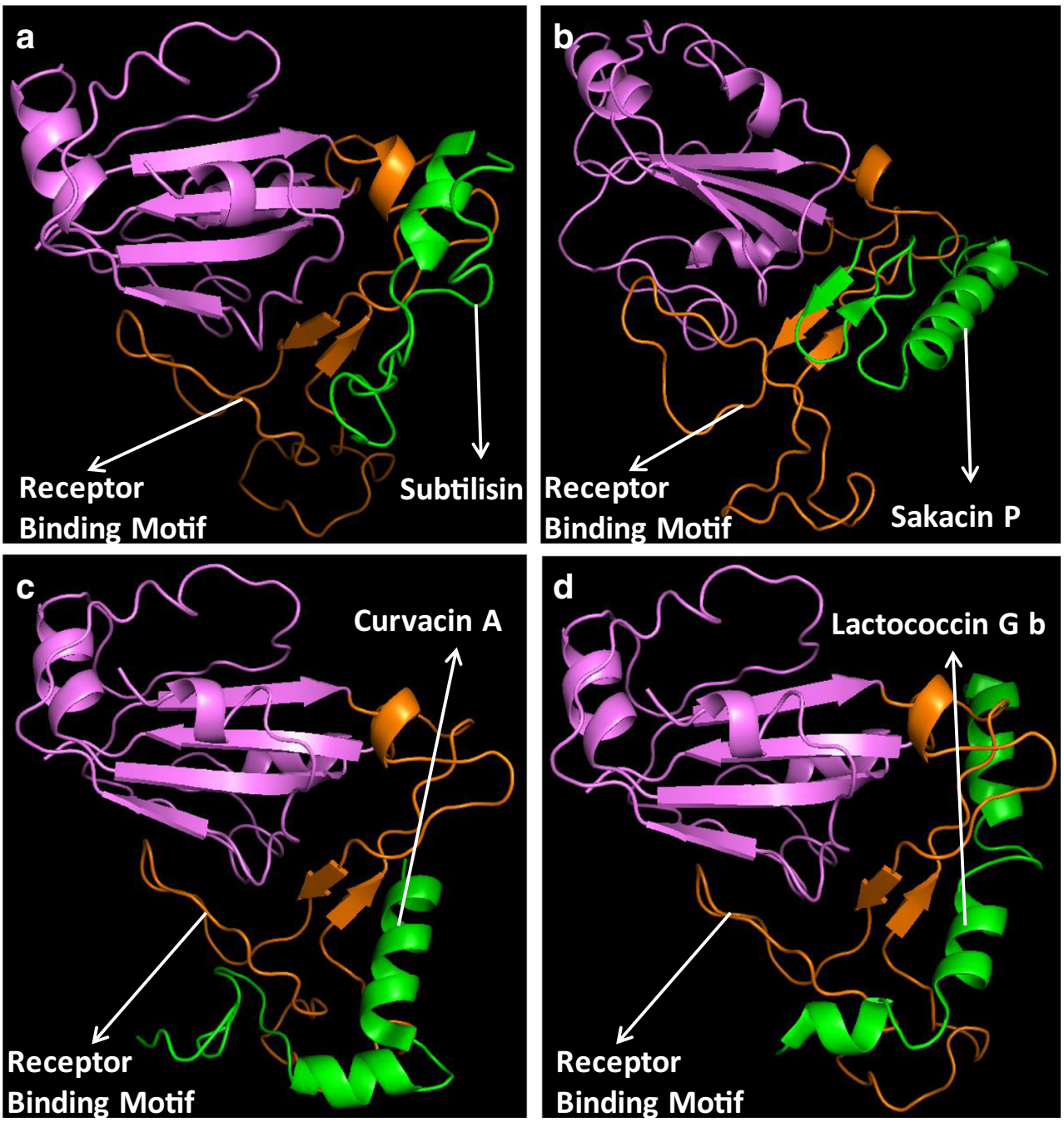

regulated by Lactobacillus acidophilus, which subsequently helps in the prevention of influenza virus infection in mice [10]. On the other hand, the cell wall of Lactobacillus acidophilus was found to control the antiviral gene expression via the Toll-like receptor pathway in mice. As of late, the danger of viral infection has amazingly expanded, and inadequacy of vaccines and drugs is imminent due to higher nonsynonymous mutations in the viral genomes, leading to amino acid substitutions in the structural proteins targeted for vaccines. Hence, under such precarious conditions, the peptides which we can derive from the probiotic microorganisms could be utilized to render a significant task to the immunomodulate human body to battle viral diseases like COVID-19.

In this article, we have summed up the potential functions of various probiotic strains against viral diseases. In silico approach was utilized to investigate the probability of probiotics-determined lipopeptides to interfere or outcompete

Table 1 Binding free energy from docking analysis based on interaction of four different polypeptides with S-protein, receptor-binding domain (RBD) of S1, ACE2 receptor, and ACE2-lipopeptide complex with S1 protein

\begin{tabular}{lllll}
\hline Interaction & $\begin{array}{l}\text { Binding free energy } \\
\text { with S1 protein }(\mathrm{kcal})\end{array}$ & $\begin{array}{l}\text { Binding free energy } \\
\text { with RBD of S1 (kcal) }\end{array}$ & $\begin{array}{l}\text { Binding free energy } \\
\text { with ACE2 (kcal) }\end{array}$ & $\begin{array}{l}\text { Binding free energy of ACE2-lipopeptide } \\
\text { complex with S1 protein (kcal) }\end{array}$ \\
\hline Subtilisin & -905.26 & -326.31 & -1250.28 & -849.01 \\
Curvacin A & -750.14 & -298.53 & -1352.01 & -857.30 \\
Sakacin P & -817.35 & -381.68 & -1180.43 & -600.09 \\
Lactococcin $\mathrm{Gb}$ & -654.24 & -253.56 & -1191.83 & -622.76 \\
\hline
\end{tabular}



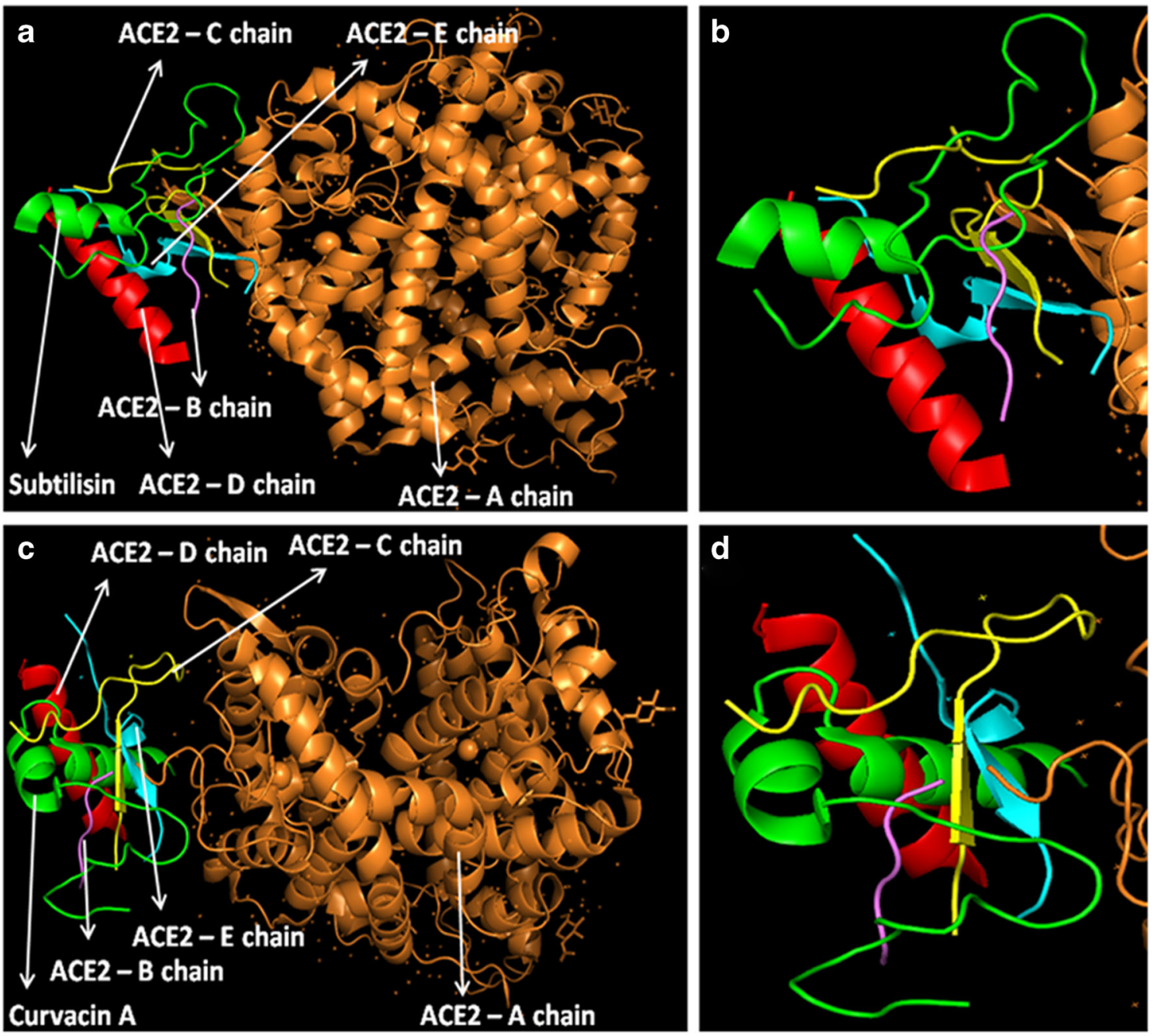

Fig. 3 Interaction analysis of subtilisin and curvacin A lipopeptides with receptor molecule, hACE2. Subtilisin docked with hACE2 protein (a), zoomed image of subtilisin ligand binding site (b), curvacin A docked with hACE2 protein (c), and zoomed image of curvacin A ligand binding site (d)

the receptor-binding domain of SARS-CoV-2 to target ACE2 receptor or by masking the receptor molecule, ACE2 binding to spike proteins of SARS-CoV-2. Hence, the noteworthy role of probiotics is investigated, which can be used in the treatment regimen to strengthen the immune defenses in fighting coronaviruses.

\section{Mechanism of Protection by Probiotics Against Viral Infection}

Defense against viral infection has also been shown by different probiotic strains (Table S1). Heat-inactivated cells of $L$. plantarum or/and L. reuteri have been found to render protection against several viral infections through reduction of granulocyte staffing and via expression of multiple proinflammatory cytokines preventing the recovery of viruses. Remarkably, L. plantarum and L. reuteri have shown prolonged existence and defense all the way through the protective mechanisms via TLR-independent pathway against the lethality induced by the pneumonia-causing virus [11]. In addition, a parallel, randomized, double blind, placebocontrolled experimental research showed that consumption of $L$. plantarum and $L$. paracasei could decrease the risk of acquiring common cold viral infections in healthy persons [12]. Probiotics additionally contain immune-stimulating biomolecules, for example, peptidoglycan, lipoteichoic acid, and nucleic acid, which are Toll-like receptor (TLR) ligands, and muramyl dipeptide, which is a NOD-like receptor ligand [13]. Here, our discussion center around the impacts of probiotics and their immunomodulatory outcomes against viral diseases including SARS.

The mechanisms of the action of probiotics in viral infections are not fully understood yet. Different probiotics showed strain-specific potential for strengthening the reliability of the intestinal epithelium and controlled the immune components. In regulating the compound-mediated immune reactions, the gastrointestinal tract from the oral cavity to the rectum is 

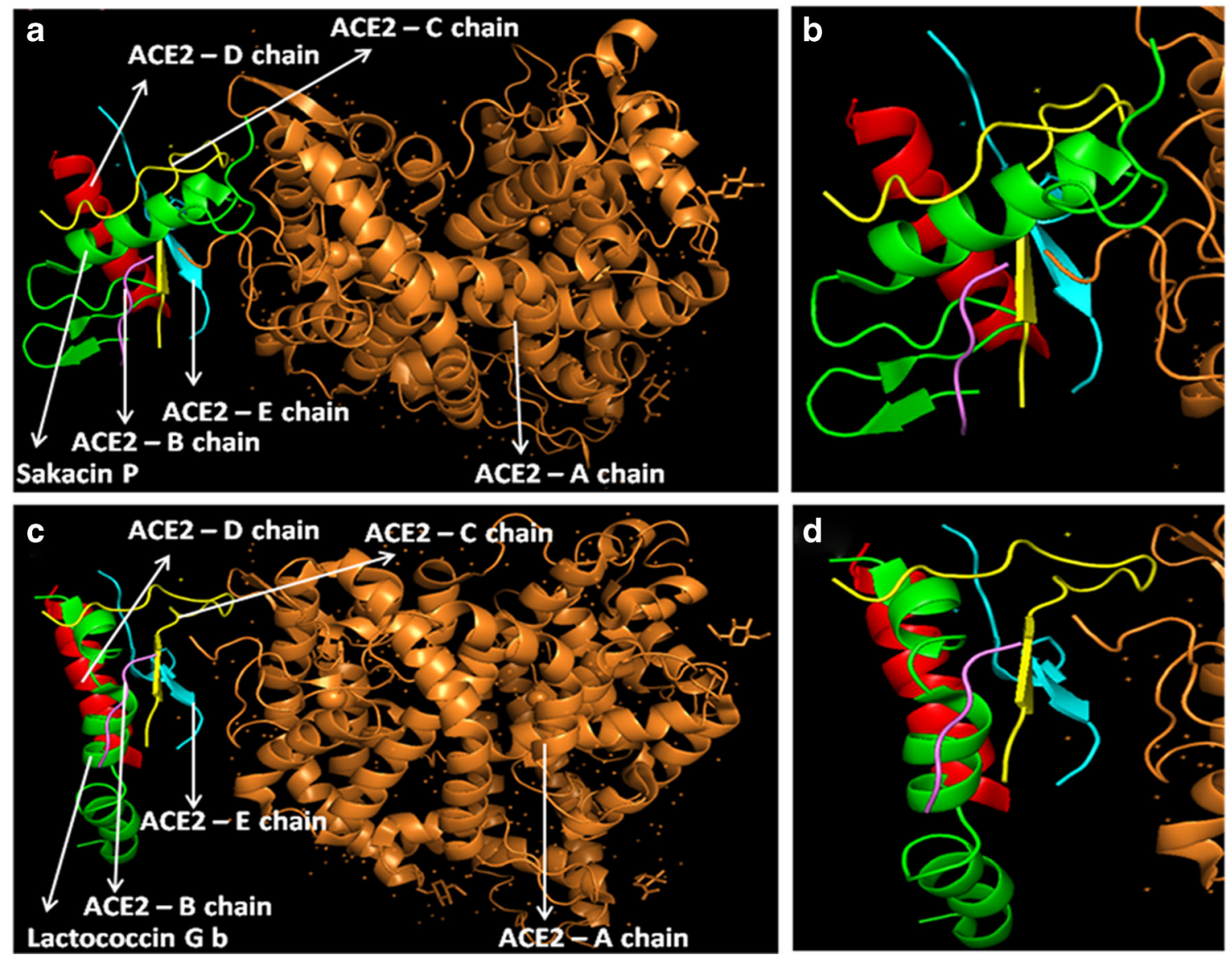

Fig. 4 Interaction analysis of sakacin $\mathrm{P}$ and lactococcin $\mathrm{Gb}$ lipopeptides with receptor molecule, hACE2. Sakacin P docked with hACE2 protein (a), zoomed image of sakacin $\mathrm{P}$ ligand binding site (b), lactococcin

$\mathrm{Gb}$ docked with hACE2 protein (c), and zoomed image of lactococcin $\mathrm{Gb}$ ligand binding site $(\mathbf{d})$

considered the major immune boundary with the environment [14]. The potential mechanisms are studied mainly in the gastrointestinal epithelium. Probiotics create intestinal epithelial defense through the production of different antiviral compounds [15]. It is confirmed that the probiotic microorganisms could tie to an assaulting virus and therefore hinder binding of the viral structural protein to the host cell receptor to prevent entry to the human cells [16].The lactic acid-producing probiotics has been found to interact directly with the virus and stimulate the immune system to produce interleukin, natural killer cells, and IgA and induce Th1 immune response activity as well. Thus, probiotics are capable of producing different antiviral agents such as lactic acid, hydrogen peroxide, and bacteriocins [17]. The antiviral impact of probiotics or their metabolites has been demonstrated [18]. Probiotics can tie with cell surfaces and influence in the primary phase of viral infection by obstructing the viral attachment to the cell receptors [19]. Another mechanism to subvert viral infection is corresponded with an immediate outcome of a probioticderived peptide, subtilisin A, in protecting against HSV-1 and HSV-2 while finding inactive against non-enveloped viruses [20]. Additionally, an intracellular mechanism has been suggested by researchers that probiotics may inhibit the steps of the viral life cycle inside the cells [21,22], inappropriately this suggestion has not been tested yet, and many questions still remain unclear that exactly what is the intracellular factor that affects the process of translation, transcription, or morphogenesis [23]. However, a significant reduction of the entrance of the virus to the cell occurred by the barrier created by the probiotics $[24,25]$.

\section{Immunomodulatory Responses During Viral Infection}

Immune response pathways are stimulated by probiotics to protect human body against the assault of infectious agents. The immunomodulatory effect of probiotics is recognized by the release of cytokines with interleukins, interferons, tumor necrosis factors, transforming growth factor, and chemokines from immune cells such as macrophages lymphocytes, mast cells, epithelial cells, granulocytes, and dendritic cells [26] which promote the regulation of innate and adaptive immune system [27]. It has been demonstrated that cell wall 

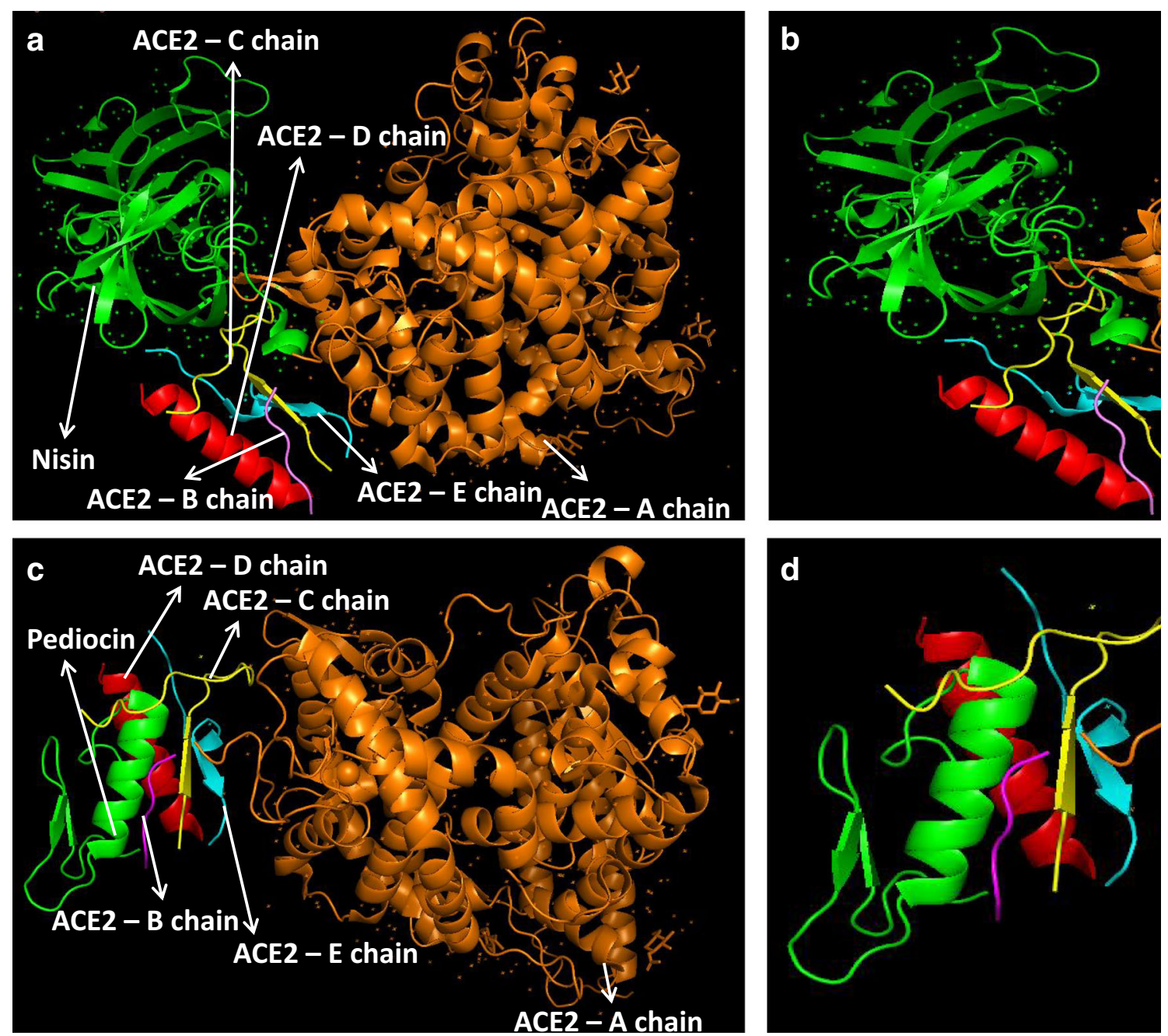

Fig. 5 Interaction of nisin and pediocin with receptor molecule, hACE2. Nisin docked with hACE2 protein (a), zoomed image of nisin ligand binding site (b), pediocin docked with hACE2 protein (c), and zoomed image of pediocin ligand binding site (d)

components of bifidobacteria and lactobacilli, such as lipoteichoic acid, induce production of NO synthase responsible for the antiviral activity mediated by activation of macrophages through the TNF- $\alpha$ secretion. Moreover, two surface phagocytosis receptors, such as Toll-like receptor (TLR) and Fc $\gamma$ RIII, are also up-regulated by NO [28, 29]. It is also hypothesized that probiotics have been interacting with dendritic and enterocytes, Treg, Th1, andTh2 cells in the intestine and modify the adaptive immunity into pro- or anti-inflammatory action. Lactobacillus paracasei DC412 strain and L. acidophilus NCFB 1748 were found to prompt early innate immune reactions through polymorphonuclear (PMN) cell recruitment, phagocytosis, and TNF-alpha (TNF- $\alpha$ ) production [30]. Furthermore, it was shown that $L$. casei was capable of activating to produce large number of specific markers such as TLR-2 and CD-206 cells [31], although TLRs are known to play a role to recover the immunological defense system in terms of pro- and anti-inflammatory cytokine production upon the recognition of foreign viral substance [32]. It is proven that the flagellin is effective against rotavirus (RV) infection as it triggers TLR5, pattern recognition receptors, and NLRC-4 that help to release interleukin-22 and interleukin-18. Both the interleukins are known to act as a regulator to switch off typical epithelial growth and promote epithelial cell apoptosis [33].

Bifidobacterium breve and the combination of this probiotic with galactooligosaccharides and fructooligosaccharides have demonstrated a defensive role against rotavirus infection by producing of IL-4, IFNg, TNFa, and TLR2 expression, although also reducing the tolerogenic response [34]. Probiotics are helpful to establish the physiological immunoregulation mechanism by activating different immune cells and subsequently destroy the viral particle. Various kinds of probiotics can enhance production of mucus and produce potential antiviral compounds like reactive oxygen species and defensins that are capable of preventing viral replication [35]. 
Fig. 6 Interaction of lipopeptide, subtilisin-hACE2 complex with $\mathrm{S} 1$ protein. hACE2-subtilisin complex docked with SARSCoV-2 (S protein) (a), zoomed image of hACE2-subtilisin ligand binding site (b), and upside down zoomed image of hACE2subtilisin ligand binding site (c)
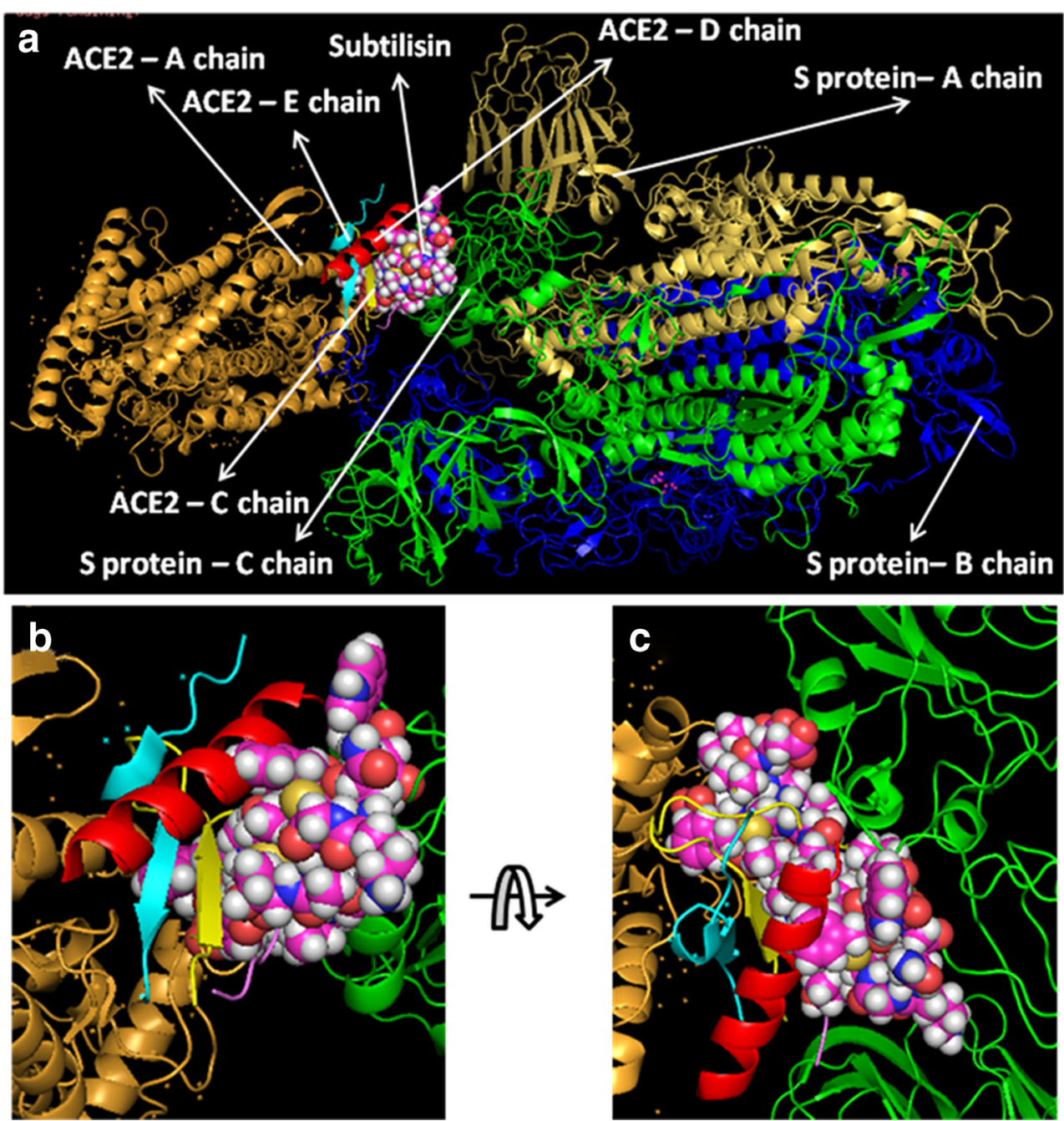

\section{Cross-Talk Between Probiotics and Respiratory Viral Infection}

Evidence proposed that probiotics of intestinal microbes not only control the local mucosal immune reaction but also have immunomodulatory effects on external sites of the gut, allied to the respiratory tract [36]. Through this mechanism, probiotics may diminish respiratory contaminations infections in healthy and hospitalized persons [37] and shield against viral and bacterial infections in the alimentary and respiratory systems [38]. There are several probiotic treatments recommended for the prevention or alleviation of viral respiratory tract infections [39]. Probiotic microorganisms have shown the property of binding to the virus particle to forestall virus's mandatory binding to the host cell receptor to enter the host cell. Probiotic bacteria are adhered on the epithelial surface and block the viral attachment by steric interference, competing for specific carbohydrate receptors or by cover the receptor sites in a nonspecific manner [40]. Mucus production is found to be increased in the presence of various sorts of probiotics; and probiotics can bind with the viruses and hinder viral replication. Probiotics additionally have indicated to direct antimicrobial action by delivering antimicrobial substances against viruses of respiratory system. Production of nitric oxide (NO) alongside dehydrogenase activity, induced by probiotics, initiated creation may have potent antiviral activities. The immune response through macrophages, dendritic cells, and the CD8+ T lymphocytes separation into cytotoxic T lymphocytes, stimulated in presence of probiotics, can wreck the infection contaminated cells [11, 41]. Probiotics can activate CD4+ T lymphocyte to produce T-assistant cells type 1 (Th1) and T-partner cells type 2 (Th2) cells. Th1 was found to invigorate phagocytes and assists destruction of the viruses of the respiratory system. Th2 cells induce the multiplication of $B$ cells, which move to the optional lymphatic organs in mucosa-related lymphoid tissue and recognize the immunoglobulin delivering plasma cells 
Fig. 7 Interaction of lipopeptide, curvacin A-hACE2 complex with S1 protein. hACE2-curvacin A complex docked with SARSCoV-2 protein (a), zoomed image of hACE2-curvacin A ligand binding site (b), and upside down zoomed image of hACE2curvacin A ligand binding site (c)
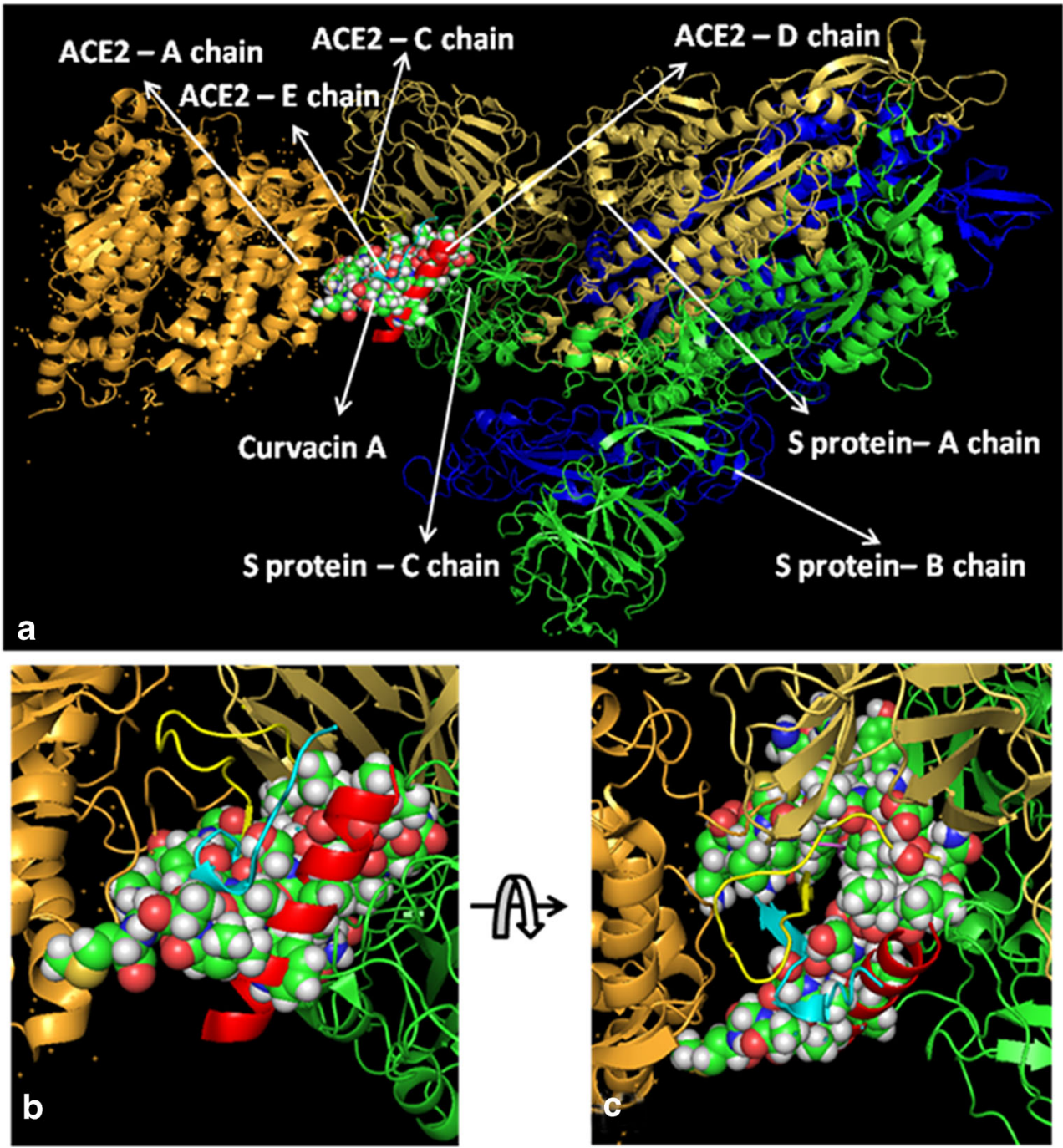

[42]. There are reports indicating that probiotics aid in easing secondary infection in the realm of viral infections [43].

\section{Probiotics Derived Peptides and In Silico Analysis}

In this study, diverse in silico experiments were done to understand the molecular mechanism of preventing spike protein to interact with human ACE2 (cell entry of SARS-CoV-2) when the system has access to probiotics-derived lipopeptides. Three targets were chosen to fulfill the abovementioned objective: (a) spike glycoprotein of SARS-CoV-2 (PDB ID: $5 \mathrm{X} 5 \mathrm{~B}$ ); (b) angiotensin converting enzyme 2 (ACE2) (PDB ID: 1R42); and (c) receptor-binding domain (RBD) of the spike glycoprotein of SARS-CoV-2 (GenBank Accession No.QHR63250.1). Four different probiotics-derived peptides, subtilisin (PDB ID:1PXQ), curvacin A (PDB ID:2A2B), sakacin P (PDB ID:1OG7), and lactococcin Gb (PDB
ID:2JPM), were docked separately with the respective targets to compare and contrast the intensity of associations/ interactions utilizing PATCHDOCK [44]. The target RBD of SARS-CoV-2 spike protein was picked up because it is the domain for binding to the human angiotensin converting enzyme 2 (hACE2) for entry into the expressing cells. Hence, our intention is to investigate the competing ability of the probiotics-derived polypeptides to hACE2 to prevent SARSCoV-2's interaction with the same target.

Preliminary screening of all docked polypeptides was done from the pool of 500 numbers of generation having maximum docked score and minimum atomic contact energy. All docked images were visualized using PyMOL and analyzed through protein-ligand identifier profiler (PLIP) BIOTEC Du Dresden [45]. The RBD present in the spike glycoprotein was chosen for demonstrating/modeling the 3-D structure of the receptor. The receptor-binding motif, present inside the RBD, is the principle reactant site. The model building of this receptor was completed using Phyre2 host following Chowdhury et al. [46]. 
Fig. 8 Interaction of lipopeptide, sakacin P-ACE2 complex with S1 protein. hACE2-sakacin P complex docked with SARS-CoV-2 protein (a), zoomed image of hACE2-sakacin P ligand binding site (b), and upside down zoomed image of hACE2-sakacin P ligand binding site (c)
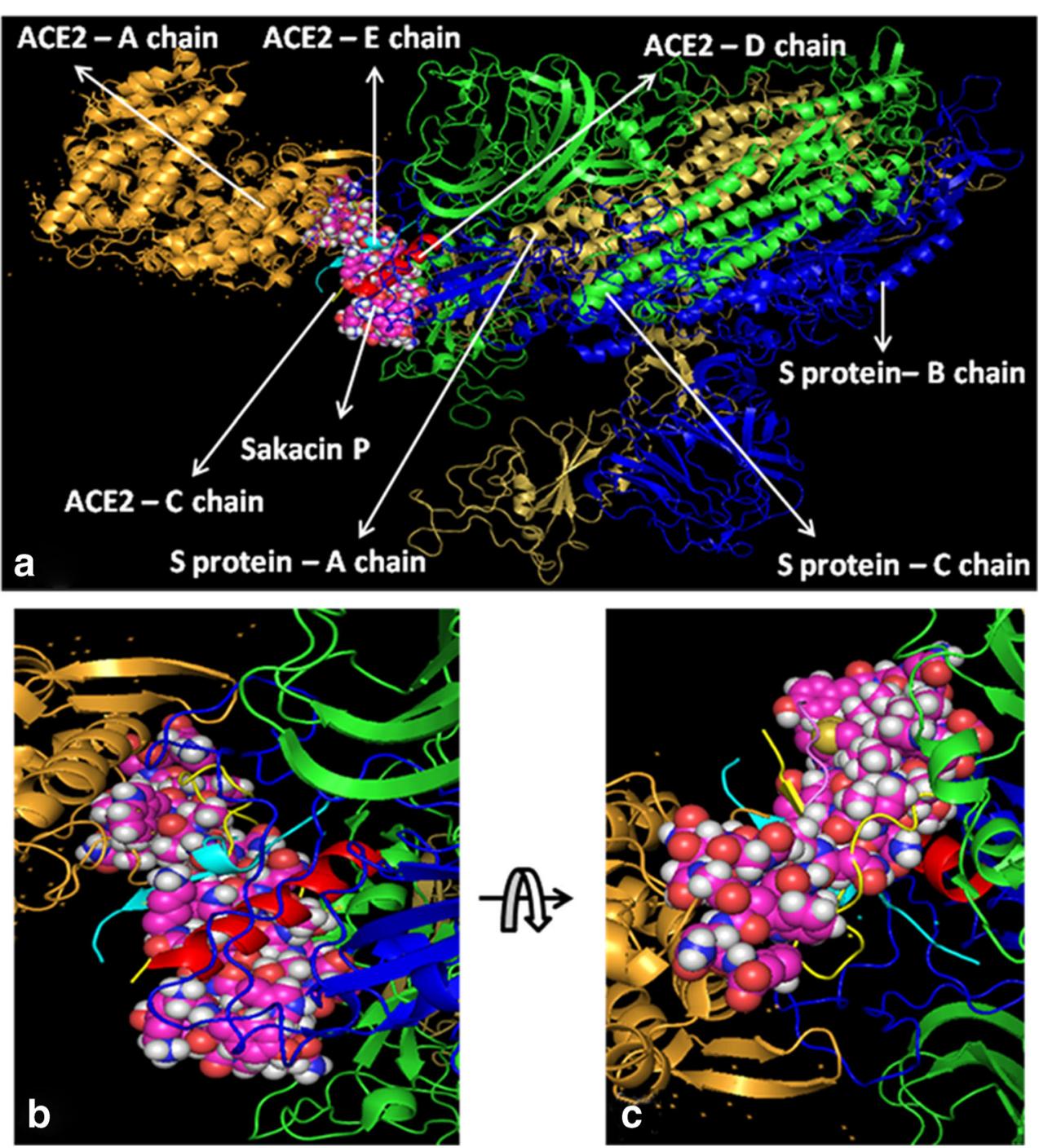

At first, all the polypeptides were docked with $\mathrm{S}$ protein of SARS-CoV-2 (PDB ID: 5X5B), and their binding energy scores corresponding to different locales of the glycoprotein were considered for further analyses (Fig. 1). Likewise, the polypeptides were further analyzed with respect to binding affinities with RBD of S1 (Fig. 2). From the in silico analyses, the binding energy obtained with each of the four polypeptides was listed in Table 1. Among the selected peptides, subtilisin, a serine protease, is obtained from B. subtilis or $B$. amyloliquefaciens and helps in nucleophilic attack on the peptide bond [47]. The bacteriocins like curvacin A and sakacin P were obtained from $L$. curvatus and $L$. sake, respectively. Both are small peptides of 38-41 amino acid residues with strong antimicrobial activity [48]. Lactococcin G-beta (LcnGbeta) is a two-component bacteriocin of 35 residues containing antimicrobial peptide, isolated from L. lactis [49]. As a transmembrane protein, hACE2 doles out as the foremost entry point into cells. More explicitly, the binding of the spike S1 protein of SARS-CoV-2 to the enzymatic domain of hACE2 on the surface of cells ends in endocytosis and translocation of both the virus and the enzyme into endosomes located within cells. Here, in silico docking of hACE2 with subtilisin molecules has clearly depicted the feasible bound-structure of hACE2-subtilisin complex (Fig. 3a and b). The position of binding was identified in the $\mathrm{B}, \mathrm{C}$, and $\mathrm{D}$ chain of hACE2 protein. The binding free energy was calculated to be $1250.28 \mathrm{kcal} / \mathrm{mol}$ (Table 1). Similarly, in silico docking of hACE2 with curvacin indicated a bound structure of hACE2-curvacin A complex (Fig. 3c and d). The interacting side chains of hACE2, B, C, D, and E where curvacin A binds were worked out (Table 1). The binding free energy was calculated to be $-1352.01 \mathrm{kcal} / \mathrm{mol}$. Likewise, in silico docking of hACE2 with sakacin P showed a bound structure of hACE2-sakacin P complex (Fig. 4a and b). Here the interacting side chains of hACE2 were found to be $\mathrm{B}, \mathrm{C}$, and $\mathrm{E}$, whereas bound structure of hACE2-lactococcin $\mathrm{Gb}$ complex has shown interacting side chains of $\mathrm{B}, \mathrm{C}, \mathrm{D}$, and $\mathrm{E}$ (Fig. 4c and d). A few well-known bacteriocin such as nisin 
Fig. 9 Interaction of lipopeptide, lactococcin Gb-hACE2 complex with S1 protein.hACE2lactococcin $\mathrm{Gb}$ complex docked with SARS-CoV-2 protein (a), zoomed image of hACE2lactococcin $\mathrm{Gb}$ ligand binding site (b), and upside down zoomed image of hACE2-lactococcin $\mathrm{Gb}$ ligand binding site (c)
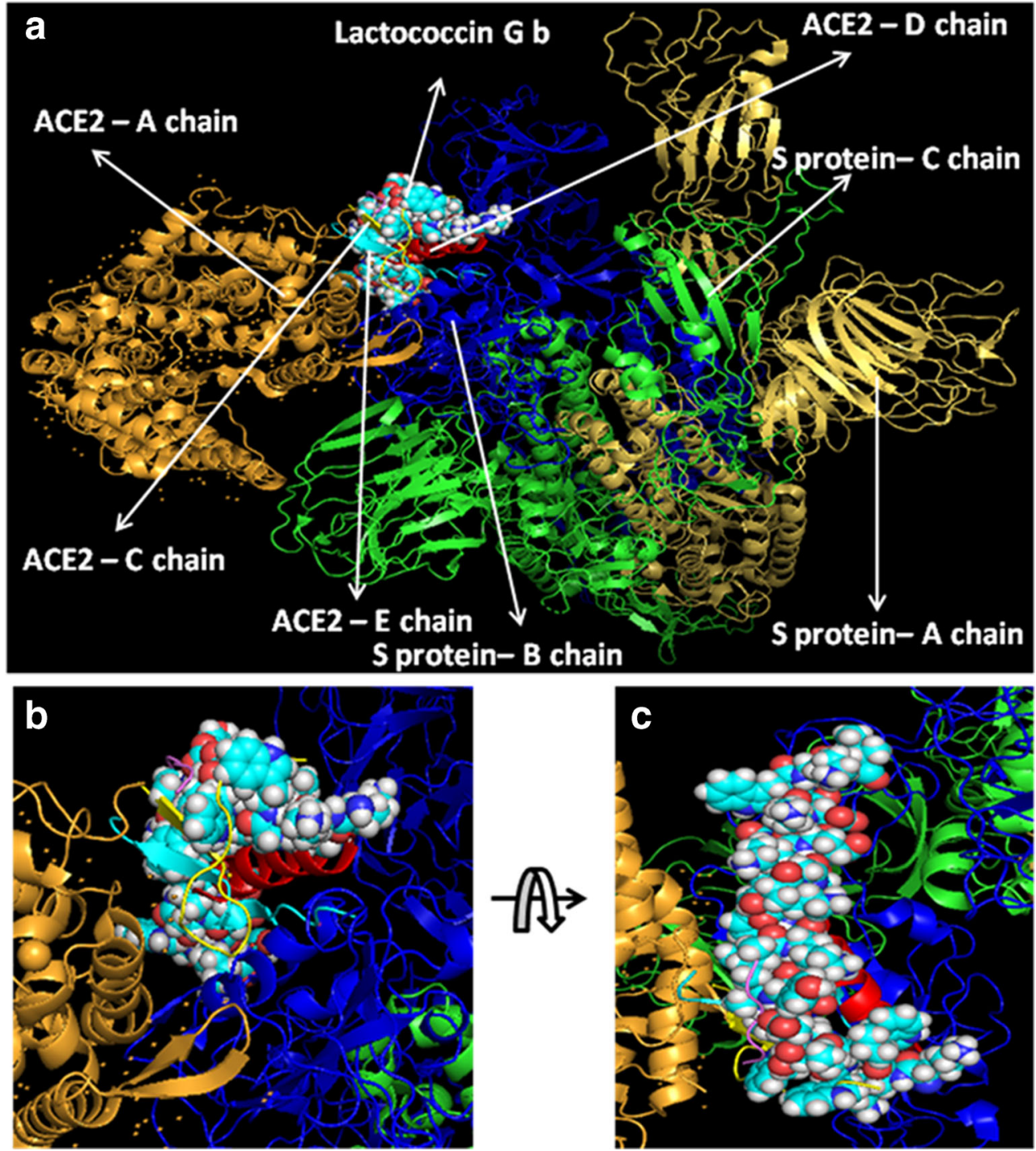

(PDB ID:5XHB) and pediocin (PDB ID:5UKZ) were also docked with hACE2. In silico docking of hACE2 with nisin showed the feasible bound structure of hACE2-subtilisin complex (Fig. 5a). The position of binding was identified in the A and $\mathrm{C}$ chain of hACE2 protein. The binding free energy was calculated to be $-296.82 \mathrm{kcal} / \mathrm{mol}$. Similarly, in silico docking of pediocin with hACE2 indicated a bound structure of hACE2-pediocin complex (Fig. 5b). The interacting side chains of ACE2 are B, C, and D chains where pediocin binds were worked out. The binding free energy was calculated to be $-782.89 \mathrm{kcal} / \mathrm{mol}$. The calculated binding free energy ($1191.83 \mathrm{kcal} / \mathrm{mol}$ ) was found to be exceptionally high.

All hACE2-peptide complexes were again docked individually with S1 of SARS-CoV-2 to check how these molecules behave with virus particles. In Fig. 6a, hACE2-subtilisin complex was docked with the S-protein of SARS-CoV-2 with a significant binding free energy of $-849.01 \mathrm{kcal} / \mathrm{mol}$, which binds with $\mathrm{C}$ chain of S-protein at the position PRO 317, THR
320, LEU 322, VAL 349, ASP 351, and PRO 513 (Fig. 6b and c). Human ACE2-curvacin A complex with S-protein of SARS-CoV-2 shows a binding free energy of $-857.30 \mathrm{kcal} /$ mol and binds with both the chains $\mathrm{A}$ and $\mathrm{C}$ in the following positions as A:TYR 163, A:SER 165, A:ASP 166, A:ALA 167, A:PHE 168, A:PHE 220, A:PRO 492, A:TYR 613, C:SER 346, C:PHE 316, C:ASN 318, C:ILE 319, C:THR 320, C:ASN 321, C:PRO 507, C:PHE 548, and C:SER 568 (Fig. 7b and c). hACE2-sakacin P complex with S-protein revealed the interaction with a binding free energy of $600.09 \mathrm{kcal} / \mathrm{mol}$. Here, the complex molecule (Fig. 8a) binds with both the chains $\mathrm{B}$ and $\mathrm{C}$ in the following positions: B:TYR 436, B:TYR 442, B:TYR 475, B:ASN 479, B:TYR 481, B:TYR 484, B:TYR 491, C:PHE 325, C:ASN 330, C:TYR 352, C:SER 353, C:VAL 354, C:ASN 357, C:SER 358, and C:ASN 375 (Fig. 8b and c). Figure 9a demonstrates the formation of hACE2-lactacoccin $\mathrm{Gb}$ complex with $\mathrm{S}$ protein of SARS-CoV-2 with a binding free energy - 


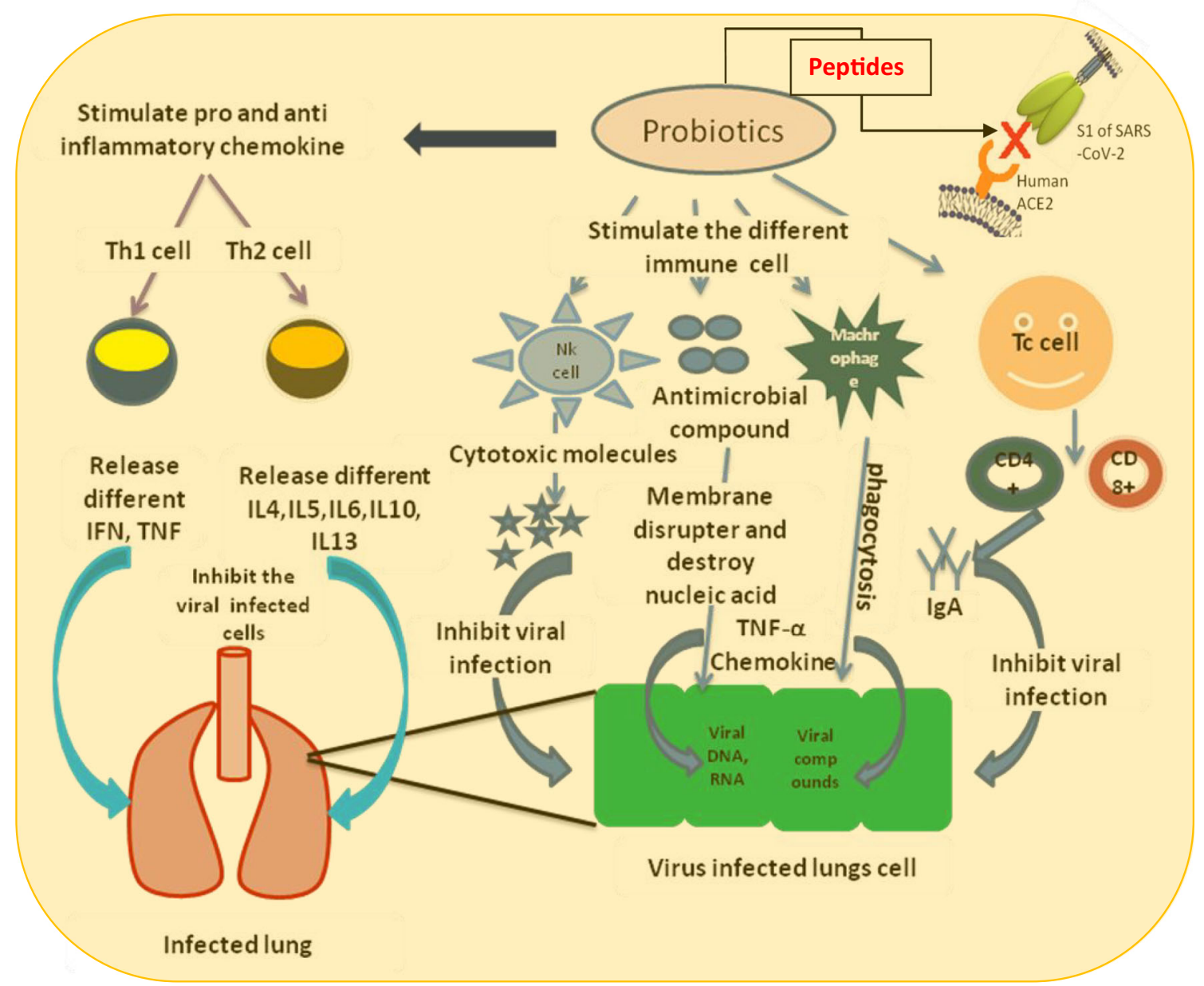

Fig. 10 Immunomodulatory and possible inhibition of viral entry pathway by the probiotics

$622.76 \mathrm{kcal} / \mathrm{mol}$. Here, the complex molecule binds with the chain B in the positions of B: PHE 329, B:ASN 330, B:VAL 354, B:SER 358, B:THR 359, B:PHE 360, B:PHE 361, B:TRP 423, and B:ASN 424 (Fig. 9b and c).

\section{Conclusion}

Probiotics-derived four polypeptides, examined in this study, have shown incredible affinity to bind with S-protein or RBD of S1, just as hACE2 receptor molecule. The interaction can be halted by blocking either RBD of S1 subunit of SARSCoV-2 or receptor molecule, hACE2. Till date, just a small number of peptides have been explored from probiotics. The probiotics can control the SARS-CoV-2 infection by two different ways: firstly as the notable immunomodulatory agent and secondly by producing lipopeptides that can straightforwardly intercept the passage of viral particles into the cell by inactivating virus's receptor molecule (Fig. 10). Since it is exceptionally urgent to save the lives from the increased fatality of SARS-CoV-2, it is hereby summed up with the overall impact of paraprobiotics or probiotics in preventing viral infection [17].We, would likewise, trust in recommending probiotics which can play a preventive role to fight against recent outbreak of COVID-19.

Supplementary Information The online version contains supplementary material available at https://doi.org/10.1007/s12602-020-09727-7.

Acknowledgments Authors are grateful to Central Research Facility, IITKharagpur, India, for providing the necessary facilities and support.

\section{Compliance with Ethical Standards}

Conflict of Interest The authors declare that they have no conflict of interest.

\section{References}

1. Jones KE, Patel NG, Levy MA, Storeygard A, Balk D, Gittleman JL, Daszak P (2008) Global trends in emerging infectious diseases. Nature 451:990-993. https://doi.org/10.1038/nature06536

2. Rather IA, Lone JB, Bajpai VK, Paek WK, Lim J (2017) Zika virus: an emerging worldwide threat. Front Microbiol 8:1417. https://doi. org/10.3389/fmicb.2017.01417 
3. Mandal SM, Manna S, Mondal S, Ghosh AK, Chakraborty R (2018) Transcriptional regulation of human defense peptides: a new direction in infection control. Biol Chem 399(11):12771284. https://doi.org/10.1515/hsz-2018-0182

4. Glezen WP, Taber LH, Frank AL, Kasel JA (1986) Risk of primary infection and reinfection with respiratory syncytial virus. Am J Dis Child 140(6):543-546. https://doi.org/10.1001/archpedi.1986. 02140200053026

5. Vijayanand P, Wilkins E, Woodhead M (2004) Severe acute respiratory syndrome (SARS): a review. Clin Med (Lond) 4(2):152160. https://doi.org/10.7861/clinmedicine.4-2-152

6. Pan A, Liu L, Wang C, Guo H, Hao X, Wang Q, Huang J, He N, Yu H, Lin X, Wei S, Wu T (2020) Association of public health interventions with the epidemiology of the COVID-19 outbreak in Wuhan, China. JAMA 323(19):1915-1923. https://doi.org/10. 1001/jama.2020.6130

7. Bahadoran A, Lee SH, Wang SM, Manikam R, Rajarajeswaran J, Raju CS, Sekaran SD (2016) Immune responses to influenza virus and its correlation to age and inherited factors. Front Microbiol 7: 1841. https://doi.org/10.3389/fmicb.2016.01841

8. Paul D, Manna S, Mandal SM (2018) Antibiotics associated disorders and post-biotics induced rescue in gut health. Curr Pharm Des 24 ( 7 ): $821-829$. https://doi.org/10.2174/ 1381612824666171227221731

9. Eguchi K, Fujitani N, Nakagawa H, Miyazaki T (2019) Prevention of respiratory syncytial virus infection with probiotic lactic acid bacterium Lactobacillus gasseri SBT2055. Sci Rep 9:4812. https://doi.org/10.1038/s41598-019-39602-7

10. Weiss G, Rasmussen S, Zeuthen LH, Nielsen BN, Jarmer H, Jespersen L, Frokiaer H (2010) Lactobacillus acidophilus induces virus immune defense genes in murine dendritic cel is by a toll-like receptor-2-dependent mechanism. Immunology 131(2):268-281. https://doi.org/10.1111/j.1365-2567.2010.03301.x

11. Gabryszewski SJ, Bachar O, Dyer KD, Percopo CM, Killoran KE, Domachowske JB, Rosenberg HF (2011) Lactobacillus-mediated priming of the respiratory mucosa protects against lethal pneumovirus infection. J Immunol 186(2):1151-1161. https://doi. org/10.4049/jimmunol.1001751

12. Berggren A, Lazou-Ahren I, Larsson N, Onning G (2011) Randomised, double-blind and place be controlled study using new probiotic lactobacilli for strengthening the body immune defense against viral infections. Eur J Nutr 50(3):203-210. https://doi. org/10.1007/s00394-010-0127-6

13. Pimentel-Nunes P, Soares JB, Roncon-Albuquerque R Jr, DinisRibeiro M, Leite-Moreira AF (2010) Toll-like receptors as therapeutic targets in gastrointestinal diseases. Expert OpinTher Targets 14(4):347-368. https://doi.org/10.1517/14728221003642027

14. MacDonald TT, Monteleone I, Fantini MC, Monteleone G (2011) Regulation of homeostasis and inflammation in the intestine. Gastroenterology 140(6):1768-1775. https://doi.org/10.1053/j. gastro.2011.02.047

15. Wan LY, Chen ZJ, Shah NP, El-Nezami H (2016) Modulation of intestinal epithelial defense responses by probiotic bacteria. Crit Rev Food Sci Nutr 56(16):2628-2641. https://doi.org/10.1080/ 10408398.2014.905450

16. Salminen S, Nybom S, Meriluoto J, Collado MC, Vesterlund S, Nezami HE (2010) Interaction of probiotics and pathogensbenefits to human health? Curr Opin Biotechnol 21(2):157-167. https://doi.org/10.1016/j.copbio.2010.03.016

17. Kassaa I, Hober D, Hamze M, Chihib NE, Drider D (2014) Antiviral potential of lactic acid bacteria and their bacteriocins. Probiotics Antimicrob Proteins 6(3-4):177-185. https://doi.org/ 10.1007/s12602-014-9162-6

18. Rodriguez-Diaz J, Monedero V (2013) Probiotics against digestive tract viral infections. In: Watson RR, Preedy VR (eds) Bioactive food as dietary interventions for liver and gastrointestinal disease.
Elsevier, San Diego, pp 271-284. https://doi.org/10.1016/B978-012-397154-8.00031-2

19. Zabihollahi R, Motevaseli E, Sadat SM, Azizi-Saraji AR, AsaadiDalaie S, Modarressi MH (2012) Inhibition of HIV and HSV infection by vaginal lactobacilli in vitro and in vivo. Daru 20(1):53. https://doi.org/10.1186/2008-2231-20-53

20. Kanauchi O, Andoh A, AbuBakar S, Yamamoto N (2018) Probiotics and paraprobiotics in viral infection: clinical application and effects on the innate and acquired immune systems. Curr Pharm Des 24(6):710-717. https://doi.org/10.2174/ 1381612824666180116163411

21. Lee DK, Kang JY, Shin HS, Park IH, Ha NJ (2013) Antiviral activity of Bifidobacterium adolescentis SPM0212 against hepatitis b virus. Arch Pharm Res 36(12):1525-1532. https://doi.org/10. 1007/s12272-013-0141-3

22. Kim MJ, Lee DK, Park JE, Park IH, Seo JG, Ha NJ (2014) Antiviral activity of Bifidobacterium adolescentis SPM1605 against coxsackievirus B3. Biotechnol Biotechnol Equip 28(4):681-688. https://doi.org/10.1080/13102818.2014.945237

23. Botic T, Klingberg TD, Weingart H, Cencic A (2007) A novel eukaryotic cell culture model to study antiviral activity of potential probiotic bacteria. Int J Food Microbiol 115(2):227-234. https:// doi.org/10.1016/j.ijfoodmicro.2006.10.044

24. Bermudez-Brito M, Plaza-Díaz J, Muñoz-Quezada S, GómezLlorente C, Gil A (2012) Probiotic mechanisms of action. Ann Nutr Metab 61(2):160-174. https://doi.org/10.1159/000342079

25. Varyukhina S, Freitas M, Bardin S, Robillard E, Tavan E, Sapin C, Grill JP, Trugnan G (2012) Glycan-modifying bacteria-derived soluble factors from Bacteroides thetaiotaomicron and Lactobacillus casei inhibit rotavirus infection in human intestinal cells. Microbes Infect 14(3):273-278. https://doi.org/10.1016/j.micinf.2011.10.007

26. Savan R, Sakai M (2006) Genomics of fish cytokines. Comp Biochem Phys D 1(1):89-101. https://doi.org/10.1016/j.cbd.2005. 08.005

27. Foligné B, Dewulf J, Breton J, Claisse O, Lonvaud-Funel A, Pot B (2010) Probiotic properties of non-conventional lactic acid bacteria: immunomodulation by Oenococcus oeni. Int J Food Microbiol 140(2-3):136-145. https://doi.org/10.1016/j.jifoodmicro.2010.04. 007

28. Delcenserie V, Martel D, Lamoureux M, Amiot J, Boutin Y, Roy D (2008) Immunomodulatory effects of probiotics in the intestinal tract. Curr Issues Mol Biol 10(1-2):37-54

29. Schwandner R, Dziarski R, Wesche H, Rothe M, Kirschning CJ (1999) Peptidoglycan- and lipoteichoic acid-induced cell activation is mediated by toll-like receptor 2. J Biol Chem 274(25):1740617409. https://doi.org/10.1074/jbc.274.25.17406

30. Kourelis A, Zinonos I, Kakagianni M, Christidou A, Christoglou N, Yiannaki E, Testa T, Kotzamanidis C, Litopoulou-Tzanetaki E, Tzanetakis N, Yiangou M (2010) Validation of the dorsal air pouch model to predict and examine immunostimulatory responses in the gut. J Appl Microbiol 108(1):274-284. https://doi.org/10.1111/j. 1365-2672.2009.04421.x

31. Galdeano CM, Perdigón G (2006) The probiotic bacterium Lactobacillus casei induces activation of the gut mucosal immune system through innate immunity. Clin Vaccine Immunol 13(2): 219-226. https://doi.org/10.1128/CVI.13.2.219-226.2006

32. Anderson KV (2000) Toll signalling pathways in the innate immune response. Curr Opin Immunol 12(1):13-19. https://doi.org/ 10.1016/s0952-7915(99)00045-x

33. Zhang B, Chassaing B, Shi Z, Uchiyama R, Zhang Z, Denning TL, Crawford SE, Pruijssers AJ, Iskarpatyoti JA, Estes MK, Dermody TS, Ouyang W, Williams IR, Kumar MV, Gewirtz AT (2014) Prevention and cure of rotavirus infection viaTLR5/NLRC4- mediated production of IL-22 and IL-18. Science 346(6211):861-865. https://doi.org/10.1126/science.1256999 
34. Rigo-Adrover MDM, van Limpt K, Knipping K, Garssen J, Knol J, Costabile A, Franch À, Castell M, Pérez-Cano FJ (2018) Preventive effect of a synbiotic combination of galacto and fructooligosaccharides mixture with Bifidobacterium breve $\mathrm{M}-16 \mathrm{~V}$ in a model of multiple rotavirus infections. Front Immunol 9:1318. https://doi. org/10.3389/fimmu.2018.01318

35. Monedero V, Buesa J, Rodríguez-Díaz J (2018) The interactions between host glycobiology, bacterial microbiota, and viruses in the gut. Viruses 10(2):96. https://doi.org/10.3390/v10020096

36. Servin AL (2004) Antagonistic activities of lactobacilli and bifidobacteria against microbial pathogens. FEMS Microbiol Rev 28(4):405-440. https://doi.org/10.1016/j.femsre.2004.01.003

37. Bodera P, Chcialowski A (2009) Immunomodulatory effect of probiotic bacteria. Recent Patents Inflamm Allergy Drug Discov 3(1): 58-64. https://doi.org/10.2174/187221309787158461

38. Guarino A, Lo Vecchio A, Canani RB (2009) Probiotics for prevention and treatment of diarrhea. Curr Opin Gastroenterol 25(1): 18-23. https://doi.org/10.1097/MCG.0000000000000349

39. Goto H, Sagitani A, Ashida N, Kato S, Hirota T, Shinoda T, Yamamoto N (2013) Anti-influenza virus effects of both live and non-live Lactobacillus acidophilus L-92 accompanied by the activation of innate immunity. Br J Nutr 110(10):1810-1818. https:// doi.org/10.1017/S0007114513001104

40. Iwabuchi N, Xiao JZ, Yaeshima T, Iwatsuki K (2011) Oral administration of Bifidobacterium longum ameliorates influenza virus infection in mice. Biol Pharm Bull 34(8):1352-1355. https://doi.org/ 10.1248/bpb.34.1352

41. Wu S, Jiang ZY, Sun YF, Yu B, Chen J, Dai CQ, Wu XL, Tang XL, Chen XY (2013) Microbiota regulates the TLR7 signalling pathway against respiratory tract influenza a virus infection. Curr Microbiol 67(4):414-422. https://doi.org/10.1007/s00284-0130380-z

42. Garcia-Crespo KE, Chan CC, Gabryszewski SJ, Percopo CM, Rigaux P, Dyer KD, Domachowske JB, Rosenberg HF (2013) Lactobacillus priming of the respiratory tract: heterologous immunity and protection against lethal pneumovirus infection. Antivir Res 97(3):270-279. https://doi.org/10.1016/j.antiviral. 2012.12.022

43. Lehtoranta L, Pitkäranta A, Korpela R (2014) Probiotics in respiratory virus infections. Eur J Clin Microbiol Infect Dis 33(8):1289 1302. https://doi.org/10.1007/s10096-014-2086-y

44. Schneidman-Duhovny D, Inbar Y, Nussinov R, Wolfson HJ (2005) PatchDock and SymmDock: servers for rigid and symmetric docking. Nucleic Acids Res 33(Web Server issue):W363-W367. https://doi.org/10.1093/nar/gki481

45. Salentin S, Schreiber S, Haupt VJ, Adasme MF, Schroeder M (2015) PLIP: fully automated protein-ligand interaction profiler. Nucleic Acids Res 43(W1):W443-W447. https://doi.org/10.1093/ nar/gkv315

46. Chowdhury T, Roymahapatra G, Mandal SM (2020) In Silico identification of a potent arsenic based approved drug darinaparsin against SARS-CoV-2: inhibitor of RNA dependent RNA polymerase (RdRp) and essential proteases. Infect Disord Drug Targets 20. https://doi.org/10.2174/1871526520666200727153643

47. Markland FS, Smith EL (1971) Subtilisins: primary structure, chemical and physical properties. In: Boyer PD (ed) The Enzymes. 3, 3rd edn. Academic Press, New York, pp 561-608

48. Tichaczek PS, Nissen-Meyer J, Nes IF, Vogel RF, Hammes WP (1992) Characterization of the bacteriocins curvacin a from Lactobacillus curvatus LTH1174 and sakacin P from L. sake LTH673. Syst Appl Microbiol 15(3):460-468. https://doi.org/10. 1016/S0723-2020(11)80223-7

49. Moll G, Ubbink-Kok T, Hildeng-Hauge H, Nissen-Meyer J, Nes IF, Konings WN, Driessen AJ (1996) Lactococcin G is a potassium ion-conducting, two-component bacteriocin. J Bacteriol 178(3): 600-605. https://doi.org/10.1128/jb.178.3.600-605.1996

Publisher's Note Springer Nature remains neutral with regard to jurisdictional claims in published maps and institutional affiliations. 